\title{
"I try and be as athletic like, forget the other side of me" - Constructions of Elite Female Wheelchair Athletes' Identities
}

\section{Af Kim Wickman}

For an athlete to participate in the Olympics is a sign of supreme achievement. The same could as well be the case for those who participate in the Paralympics, the equivalent of the Olympics. The way elite female wheelchair atbletes talk about themselves and their sport and their experience of being positioned by others and the way they position themselves will be discussed in this paper.

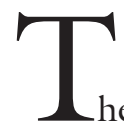

he first Paralympic Games were held in Rome in 1960 (Guttmann 1976). As with the Olympics, the Paralympics are held every four years, typically about three weeks after the Olympic Games. Even though the Paralympic Games is growing, women and some disability groups are still underrepresented (Craft 2001, Scherrill 1997, Grey 1996). In the Sydney Paralympic Games 122 countries participated. However, of the 4032 athletes who competed only one third of the participants (1019 athletes) were women (Craft 2001).

Feminist issues in regard to Paralympics have begun to appear in the literature (DePauw and Gaveron 1995, Kolkka and Williams 1997, Schell and Duncan 1999, Tomas and Smith 2003). Although, according to Scherrill (1997) researchers need to carry their concerns into the real world of public schools and sports organisations to enhance opportunities for women in sport socialization, training, competition, and administration. 
This paper is based on interviews with five female wheelchair racers. It also reflects my commitment to feminist theory and Poststructuralism which offers, as I see it, useful tools to analyze and illuminate the realities of female wheelchair racers on top level which hopefully will contribute to a greater understanding of the complex interactions of gender, disability and sport. My intention is, however, not to speak for women with disabilities but rather to write what I can observe from my viewpoint as a researcher and with my own experiences of teaching sports for people with physical disabilities. Further, useful experiences have been gained from my own training as an able-bodied female wheelchair racer.

\section{THEORETICAL APPROACH}

According to Hargreaves (2000) there are ideological, social and political structures of power that affect the lives of people with disabilities in essential ways. From a historical view people with disabilities have had (and still have) little opportunity to portray their own experiences within the general culture. As Morris (1993) explains it "When researchers approach people with disabilities as a research subject, they have few tools with which to understand our subject reality because our own definitions of the experience of disability are missing from the general culture" (p. 64). Even though, the view that gender is not biologically determined has taken a much more radical turn in feminist poststructuralist criticism, where the symbolic and cultural significance of women's bodily differences from men are closely examined, aspects of disability and gender have been almost entirely ignored by feminists (Morris 1993). According to Wendell (1997) feminist perspectives on disability are not yet widely discussed, nor have the insights offered by women writing about their own experiences of disability been integrated into feminist theorizing the body. Further, with regard to Blinde and McCallister (1999) the knowledge of the experience of women with physical disabilities in sport and physical fitness activities are limited.

Not only has the female body been represented as deviant, but historically the practices of femininity have configured female bodies in ways that duplicate the parameters of disability. Feminizing conventions such as Chinese foot binding, African scarification, Euro-American corseting have been socially accepted, encouraged, and in some instances even compulsory. These are forms of female disablement that ironically constitute feminine social enablement, increasing a woman's value and status as a woman at a given moment in a particular society (Garland Thomson 1997). The message we are given daily by media is that women must look a certain way to be loved and admired, to be worth anything. As Asch and Fine (1997) express it "However, if men desired only the passive doll-like female of stereotype, women with disabilities might do, but the doll must be functional as well as decorative" (p. 244). In a culture which loves the idea that the body can be controlled, those who cannot control their bodies are seen (and may see themselves) as failures (Wendell 1997).

One could say that poststructuralist theory contributes to a reflexive awareness of the constitutive power of language (Davies 1997). With regard to gender, its production and change, women can be understood as shaped by or within the structure of language and meaning. Discourse is fundamental with regard to what is possible to express in talk and text within a specific social and historical context. Additionally, it works as a regulator of what is possible to think and do and who is able to speak, who will be silenced and who will not be able to make their voice heard in a certain context or according to a certain issue (Mills 1997). In that sense, language constitutes our social reality and from that perspective, discourse can be stated as a distinctive way 
of talking and thinking about different phenomena (Johansson 2003). The subject is, however, not simply determined by one particular set of meanings and has certain possibilities of moving within the discourse and is not solely restricted to a previously determined pattern (Jones 1997). Further, the subject is able to occupy several subject positions in different discourses at a time. Thus, some of these positions are available to the subject, some are not, and a position can be more or less desirable according to the subject (Mills 1997). Nevertheless, almost all discourses concerning different aspects of the social world contribute in one way or another to maintain normalities and consequently what will be defined as deviancies (Corker and French 1999).

\section{OVERALL RESEARCH QUESTIONS}

The overall aim is to analyze wheelchair racing as a discourse. The following question is posed:

How do the discourses of disability, competitive sport, and gender interact in the discourse of wheelchair racing, as women wheelchair racers talk about themselves and their sport?

This question also concerns the way they simultaneously construct their identities by accepting or resisting the subject positions provided by the discourses.

\section{The InVESTIGATION}

The paper is based on one-to-one semistructured interviews with five female wheelchair athletes. Regarding the selection process these five women constituted the complete national team of female wheelchair racers at the Paralympic Games in Sydney 2000. In this study the Paralympic Games are applied as a backdrop against which the athletes and their experiences are contemplated. Additionally, the interview questions were designed to allow the ath- letes to talk about issues that they felt were important to their own elite career: for instance, how they once went into the sport, role models, gender issues, financing and sponsorship, relationships to coaches and trainers, and media attention. In short, everything involved in being a top elite female athlete with a physical disability.

In the process of designing the interview guide, the questions were tested on two female athletes with physical disabilities to determine the appropriateness and clarity of the questions. All the interviews were conducted by me, the researcher, and the responses were tape-recorded and transcribed. The athletes were asked to choose where the interview should take place and each woman was interviewed privately for approximately 70-90 minutes. All the interviewees were made aware that they could decline to answer any question and terminate the interview at any time. At the end of the interview they were allowed to add anything they believed to be of importance and later, after the interviews were transcribed, the interviewees also had the opportunity to review the transcripts and make corrections or additions.

All the interviewees in this study have varying degrees of physical paralysis. While all five women routinely use a wheelchair, three women were born with their paralysis and the remaining two sustained traumatic spinal injury. All of them had previous experience of different sport activities on both competitive as well as non-competitive participation levels. At the time of the interviews, three of them were still active at the elite level and two had retired but had not taken a definite decision whether to continue with wheelchair racing or not.

The three specified discourses explored in this study constitute the starting point of the discursive construction of three different social categories that 'exist' as discursive constructions in the society in terms such as 'woman', 'disabled', and 'elite athlete'. Hence, I will argue that there are ex- 

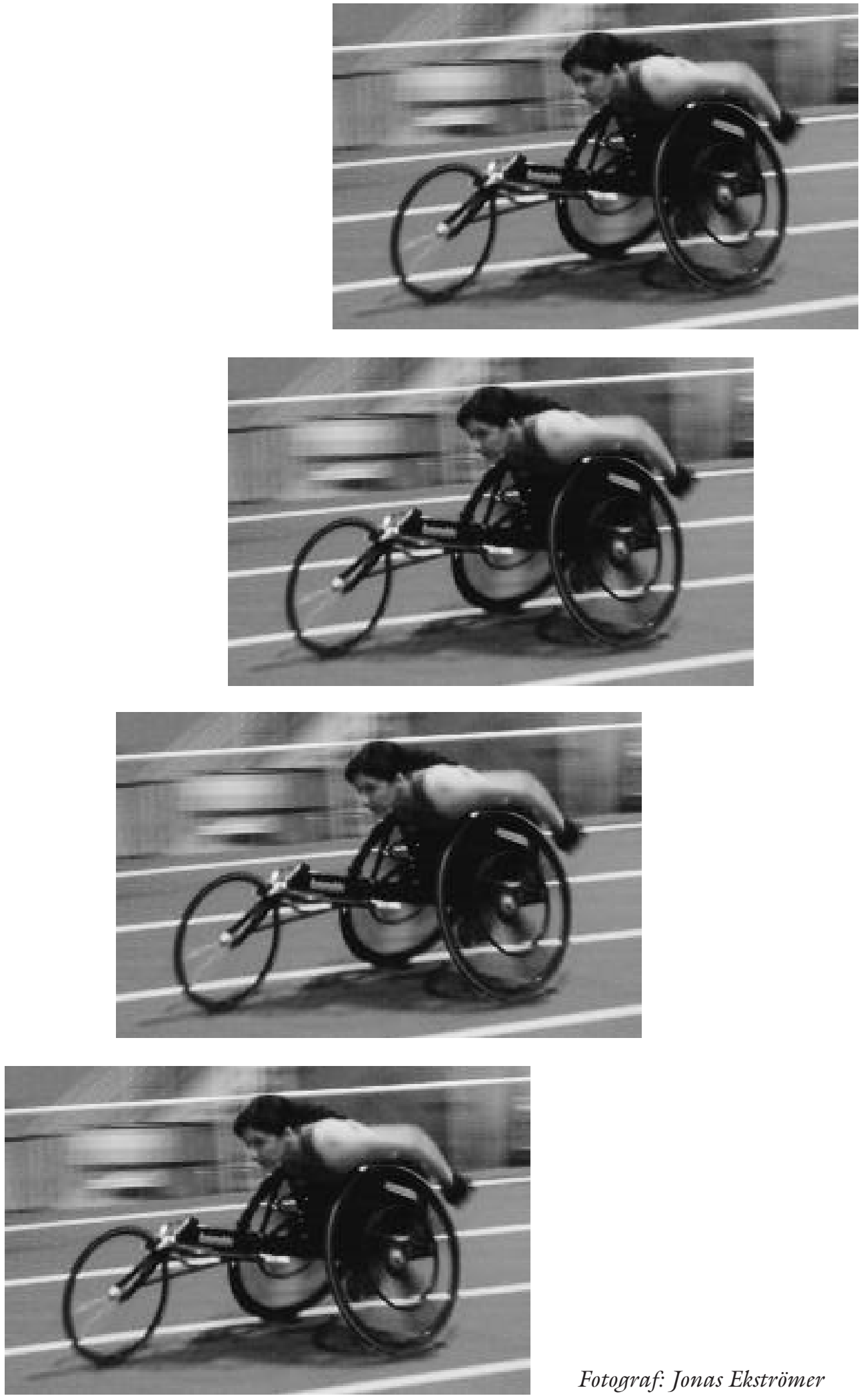
isting dominating discourses about gender, physical disability and competition that, so to speak, fill these categories with meanings. From a poststructuralist view my empirical data illustrate how the interviewees will position themselves and how they experienced that they were positioned by others. Additionally, during the working process, there has been an interaction between theory and empirical data.

\section{THE WHEELCHAIR RACING}

\section{AS DISCOURSE}

\section{Competition discourse}

In all organized competitions, in individual as well as team sports, it is a matter of achieving as high ranking as possible, by permitted means and within the rules appropriate to each sport. To win and to break records is thus the ultimate goal. Competition is, purely in terms of time spent, a relatively small part of active sports or athletics; training is what dominates. Demonstrating one's superiority in athletic achievement is also a feature of competition discourse; one's position as superior is always threatened, because fellow competitors fight for the same desirable position. It is part of competition to improve one's athletic ability and to compare oneself with others (Patriksson 1982, Engström 1999). Finally, our physical ideals change from time to time, but we always have ideals. These ideals are not just about appearance; they are also ideals of strength and energy and proper control of the body which is a central aspect in regard to the competition discourse (Wendell 1997).

\section{Disability discourse}

In a society that idealizes the body, the physically disabled are marginalized. Further, people with disabilities are often associated with bodily weaknesses, inabilities, or illnesses (Wendell 1989). There is also the idea that the person with a functional impairment should show gratitude for the compassion and assistance that the individual concerned may receive from able-bodied people and from society at large (Davis 1995). For the able-bodied, people with disabilities often symbolize failure to control the body and the failure of science and medicine to protect us all. 'The disabled' is a category of 'the other' to the able-bodied and usually depicted as victims of natures or accident. In that matter, relatively few people can identify with those who cannot be 'repaired' by medical intervention (Wendell 1997). Traditionally, when people with disabilities have been encouraged to participate in sport, it has often been as a part of a rehabilitation program (Thomas and Smith 2003). However, some people with disabilities become symbols of heroic control against all odds; these are the 'disabled heroes' who are comforting to the able-bodied because they reaffirm the possibility to overcome the body (Hargreaves 2000). Disabled heroes are people with visible disabilities who receive public attention because they accomplish things that are unusual even for able-bodied (Wendell 1997). A woman with disability is rarely contemplated as wife, mother, or worker (Asch and Fine 1997).

\section{Gender Discourse}

In most societies humanity is divided into two genders. What is regarded as masculine and feminine, however, varies over time and between different cultures. Butler (1999) argues that there are discourses which form meanings within a culture and in that sense dominating notions about for instance what it means to be a good mother or to be a heterosexual desirable object etc. Our notions of masculinity and femininity are ruled by gender stereotypes and the woman is depicted as the antithesis of the man (Wendell 1989). The normative female body - the figure of the beautiful woman - is a narrowly prescribed version of what the ideal male figure is not. If he is 
to be strong, active, hirsute, hard and so on, then she must be the opposite - weak, passive, hairless, soft and so on. Traditionally, white middle-class women's experiences have been taken as the norm and other women's experiences have been treated as 'different' (Morris 1993). Additionally, the further a female body departed from absolute beauty, the more 'abnormal' it became as a female body (Garland Thomson 1997). In short, the woman with disability is not only defined against the masculine figure, but she is imagined as the antitheses of the normative woman as well.

\section{TO BE AN ACTING AND PARTICIPATING} SUBJECT IN THE WHEELCHAIR RACING DISCOURSE

In the text that follows, some of the interview responses are reproduced, and following these are brief reflections and interpretations. The answers by the interviewees are stated separately, but at times a comparison is made between the responses when the stories reinforce or contradict each other. All the individuals who appear in the text have been given pseudonyms. The five female wheelchair racers have been named Jackie, Cynthia, Stella, Jane and Lisa.

The following quotation illustrates all three discourses:

"I had blue hair and an eyebrow ring and was pretty loud/.../ Before the Paralympics the head coach of the training camp, who I am sure did not like me said 'oh you should tone it down a bit', because I used to wear a bit of makeup and I had really long red plaits which they thought was not good and that made me really depressed 'cause I don't think it had anything to do with it. Fair enough that they got angry at me for not training enough that's completely fair but when people are prejudiced against you because you look a bit different. /.../ while others like Nick who is covered in tattoos, I don't get why they picked on me. /.../ I think it would have been different if I was a guy" (Jackie).

The competition discourse is reflected in the fairness pathos which Jackie is expressing when she shows her acceptance of the relation between lack of training and nonappearance in competition. She, however, resists the attempts by her head coach to make her tone down her personal style. The criticism, which she feels, and her resistance to it can be interpreted as a conflict between her and her head coach concerning the gender norms for female appearance, behaviour and demeanour. In the quotation above, the discourse of gender appears once more when Jackie compares herself with the male wheelchair racer, who is here called Nick. Despite the fact that he, like her, has a rather sensational appearance, Jackie feels that people around him show greater acceptance and allow him greater scope for action and then concludes that the situation would probably have been different if she had been a man. What Jackie expresses, may also be interpreted as a revolt against the disability discourse where the 'disabled' person is expected to be obliging and grateful and thus receptive to people's benevolence and empathy. One who consciously chooses a provocative appearance may be seen as unwilling to receive people's help and support.

In the next quotation, there is both strong resistance to, and compliance with, the media's watching and positioning of athletes with disabilities.

"A lot of bad articles written focus on these 'poor disabled people' that happen to be successful wheelchair athletes./.../ people always “oh I don't want to offend you but can I ask why you are in a wheelchair" It can be annoying but I hate explaining all the things. I think I am sometimes curious why people are in chairs because some have really interesting stories and sometimes you can lie to people, like you got hit by an ice cream truck, 
they always want to know what happened, and I think it is only polite to tell them" (Jackie).

Jackie's words reflect a form of ambiguity towards the way people treat her in connection with the disability she has. While she sometimes feels insulted when people ask her why she is in a wheelchair, she also feels obliged to be polite and answer their questions. Her statement also demonstrates resistance and compromise concerning the disability discourse. By sometimes replying that she was run into by an ice cream truck, she accommodates people's curiosity and a dominant idea about 'the right to know'. One might say that in not revealing her own story she has created a form of agency and space within the disability discourse. Jackie concedes that she, too, may feel curious about the life stories of other people with disabilities. The fact that she herself can experience curiosity strengthens her understanding of other people's curiosity, something which may perhaps reinforce the feeling of wanting to oblige. As Wendell (1997) puts it: "Many people with disabilities are tired of being symbols to the ablebodied, visible only or primarily for their disabilities, and they want nothing more than to be seen as individuals rather than as members of the group "the disabled".

It does not appear to be Jackie's own experiences of 'a tragic life', which create a sense of failure, but rather the reactions of other people. On one hand, Jackie shows resistance and unwillingness to being positioned as different and divergent with regard to the disability and the fact that she uses a wheelchair. On the other hand she uses symbols and attributes as the eyebrow ring and the tattoos, which can be interpreted as her way to lay claim to a position outside the discourse of normative gender ideals.

At the time of the interview, Cynthia had just moved from a smaller town to a city in order to improve her chances to develop her sport. The competition discourse appears clearly in her story.

"Wheelchair racing is one of the very clear directions I have in my life right now. I may be doing economics, but I have no clue what I am going to major in or where I want to work. I presume I don't know until I get a job. With wheelchair racing I know what I want to do. I know where I want to go" (Cynthia).

According to Wendell (1997), many people with disabilities who see the possibility of living as independently as any other ablebodied person, or who have achieved this goal after a struggle, value their independence above everything which is obvious in Cynthia's case. Beyond her academic studies she invests time and effort in a sporting career, and so she might be seen by the general public as 'normal'. Cynthia, however, expresses a sense of being an outsider. The physical impairment, she has, is constantly in the foreground. Thus it is not a matter of course to be regarded as an independent young woman, university student and elite sportswoman. The quote below may be regarded as resistance to being positioned according to the disability discourse.

"I think I have been too open, now I try and be as athletic like, forget the other side of me, come from an athletic point of view and explain what I do and limit the information. $/ .$. /I have spent a lot of time in my sport and wanted to be respected, I do not want people to think of me for the wrong reasons and I am quite conscious of what people think" (Cynthia).

Cynthia says that in the last few years she has altered her tactics in her encounter with journalists, in order to lessen their attention to the disability and focus instead on the sporting achievement. This fact can be interpreted as an impulse to connect with the 
competition discourse and at the same time distance herself from the disability discourse. She says that she has invested great effort in her sport and therefore cannot accept that the media distorts the image of her as an elite sportswoman. The way Cynthia handles the media is expressed by her awareness of the logic of the discursive game. Further on, Cynthia says she believes that as a competitive athlete one has to be special or have something which is unique, in order to be noticed by the media.

“They do pick up on prettier girls and also ones with less disabilities. Track athletes always get more media attention. You notice that we have a couple of pretty amputees and they always get more media attention./.../ I think sport is an independent action; I find that women are not that independent. /.../ I think you find that with the guys the competitive instinct is there a lot more than with the women. The girls are more worried with how they look whereas the guys just get on with it. They have different attitudes" (Cynthia).

Cynthia compares amputees and wheelchair racers and indicates that wheelchair racers have a subordinated position within the competition discourse in relation to amputee track athletes. According to her, having a less extensive functional impairment and an attractive appearance provides greater opportunities for media attention. Here we also discern a ranking principle, based on the idea that the further from the ideal, that is to say the norm, the individual finds herself, the worse their chances are of acceptance and success. Nevertheless, she implicitly contributes to the reproduction of the stereotypes that she essentially is critical about.

The ambivalent attitude towards the physical impairment appears here, just as in Jackie's story. There is a contra-productive stance toward people's noticing the disability. The disability arouses attention which it is not always easy to disregard. A strongly contributing factor is, for instance, that wheelchair racing as a sport presupposes that the competitor in one way or another is in need of a wheelchair in daily life and not only use a racing chair during a particular sport event. This fact, like the competitor classification, has its basis in the disability. Completely to disregard the impediment in every context would, however, be to deny one's self. In both Cynthia's and Jackie's stories it is clear that they strive to construct themselves as full value elite athletes in accordance with the competition discourse. Nevertheless, as a consequence of people's questions and curiosity regarding the disability they are constantly forced back into the disability discourse.

Stella latches on to the disability discourse and like Cynthia she is of the opinion that there is a ranking principle at work within both the disability discourse and the gender discourse. A person with a less extensive physical impairment, or one who has an acquired disability, has a higher status than those who have an extensive or a congenital physical impairment. In the gender discourse it is the person who looks attractive who catches the attention of the public and the media.

"There are the glamorous disabilities and the not so glamorous disabilities. /.../ Amputees are as close to normal as you are going to get and the not so glamorous are the Cerebral palsy and the lower class./.../ I think media is full of perfect images, whatever the Paralympics can produce that is closest to perfection is what they are going to pick, unless there is something outstanding about a different group. Yeah sometimes I think it is a bit of a shame. /.../ You have a lot of journalists that say 'so you suffer from', and I prefer you don't really put that in print, we are sick of seeing that. /.../ People attempt to say what's politically correct but underneath the disability it's still such an issue. $/ \ldots /$ If it wasn't an issue it would not be coming up but it comes up repeatedly. So 
therefore I think it is an effort to understand it" (Stella).

In Stella's story, too, we find the compromises in relation to answering people's questions focussing on the disability. Stella provides further instances of the way in which the media image of athletes with disabilities is affected by a stereotypical disability discourse.

"I think there is still a fair few out there that are looking at what is going to sell the papers and make the front page. Unfortunately perhaps they believe it will be a 'warm and fuzzy story', and that is the problem with a lot of the articles. I have an article that makes a huge deal about how brilliantly bonded our team were, but they took it to the extreme, so they are pushing the warm and fuzzy image, you miss some of the reality of the competitive level of the sport" (Stella).

Stella does not accept to be constructed in resemblance with the norm, which prescribes that a woman should be focused on relations rather than on competition and performance. If men are depicted as strongly determined to win, this is in accordance with the competition discourse. Perhaps that's the reason why Stella does not identify herself as an athlete with the "warm and fuzzy image" which perhaps can be seen as an expression of a normative gender discourse. If so, she does not adhere to stereotypes of how a woman should be. Stella positions herself as a wheelchair racer and thus adopts the competition discourse in her description of herself.

According to the gender issue, Jane articulates a gender discourse of equality in which women should be valued in resemblance with the same norms as men but without being subordinated. When she compares able and disabled athletes and thus latches on to the disability discourse, her words reflect a difference in sponsoring and media interest. Jane emphatically marks her resistance towards the disability discourse and, like Cynthia, she adopts the competition discourse.

"Able-bodied athletes are always going to be ahead of us I think. Definitely, it's just the way it is. /.../ I don't want to be patronised and I am sure nobody else does either. I don't do this sport as part of rehabilitation or part of just fun or getting out there. I do it because it is fun but I am very competitive" (Jane).

Jane illustrates the truth effect of the disability discourse when she says; "It's just the way it is". However, Jane thinks that the process of changing the public's notions and appreciation of wheelchair athletes and their sporting achievement is slow and takes time. Further, Jane is the only one among the five interviewees who is a professional wheelchair racer and she has gained a great deal of attention as an athlete during her career. Jane, however, questions the idea that athletes with disabilities should be grateful for the compassion showed toward them.

"Myself I have had fantastic recognition and I have been recognised on an equal level many times as the able-bodied athletes but in general wheelchair races or athletes with disabilities don't get the same recognition or respect or the funding that able-bodied athletes do" (Jane).

To sum up, Jane strongly adopts the competition discourse and her position as a wheelchair racer. Like the other interviewees she has mixed experiences of encounters with the media and the general public, but unlike the others she has a predominantly positive impression. Like Jackie and Cynthia, she is consciously acting to influence people's ideas about wheelchair racers and their sport, something that also causes Jane to try to deal with questions about the physical impairment she has. 
Lisa believes that people generally do not regard wheelchair racing as a serious competition sport but rather as a form of exercise.

"We are professional athletes that train full time and really hard to do what we do /.../ What I am saying is that people think you just go sign up somewhere and you go and compete in the Paralympics, and no one wants to know how much training you have done and that's the feeling I get from people who don't know" (Lisa).

Lisa resists the disability discourse very strongly. In her statement she adopts the competition discourse and thus is quite clear about her disapproval when the competition organizers lower the cut in the selection rules for the competitors. Lisa's story can be interpreted as a way of distancing herself from the disability discourse. Instead, she prefers to position herself within the competition discourse by emphasising the 'rules of the game'. In that way she implicitly claims the same status and value as competitors in other competitive sports. Again similarly to Cynthia's story, the impairment she has often ends up on front stage. Lisa expresses a certain watchfulness mixed with resignation regarding the general public's conceptions of the ways a person with a physical impairment should be and should behave. In the next quotation Lisa refers to different events with sportsmen - and women with disabilities. Although she expresses her resistance against the stereotypes of the disability discourse, she concedes that she is herself affected by it:

\section{“/../ if I was going to watch an event I would probably want to see the most able, active event I could. I would rather go to wheelchair racing, or basketball, because I want to see more action and I want to see people with ability and using that" (Lisa).}

As in the stories of the other women, a contradictory and ambivalent stance towards the positions of the disability discourse is apparent in the above quotation. This may be an indication of the strength of the disability discourse, that appears in different disguises and thereby strongly decreases Lisa's possibilities to attain the same status and value as the abled athlete. Despite her insight and experience of discrimination and her constant resistance against the stereotypes of the disability discourse, Lisa too is affected by the normative image of appearance, being and behaviour of a competition athlete. By stating that she would rather watch a competition with less disabled participants, she indirectly reinforces the picture of the athlete with disability as the 'non-desirable other'.

\section{CONCLUDING REFLECTIONS}

According to these female wheelchair athletes the physical impairment has given them access to another discourse, namely the competition discourse, which logic at least not a priori defines them as deviant. However, the interplay between the latter and the disability discourse contributes to a definition of being deviant to a certain extent within the competition discourse as well. However, no matter what way the issue is turned and twisted, a visible impairment will always create curiosity on the part of the observer. Considering that these women compete in a sport which was created with disability as a starting-point, people's curiosity and questions as to their individual stories about the way they ended up in a wheelchair are inevitable. These women have mixed feelings of resistance and responsibility to provide an answer, especially when questions quite often are felt to be about private, rather than professional, matters. Apparently they do not willingly let people position them as disabled; it is a position they more or less try to avoid. However, it is difficult, since the 
wheelchair constitutes a central aspect of their sport and as the impairment is a part of their identity. On the one hand, they are top level athletes and different from people in general in an advantageous way, just like able- bodied athletes who are considered 'star quality'. At the same time they are looked at as disabled and in that matter unable to fulfil the 'star quality criterion'. What is obvious in these women's stories is, however, that they cannot be contemplated as passive objects unable to affect their own lives. Rather, they seem to be well aware of the logic of the discursive game and thereby manifest their independency through action and resistance. Further, they have been able to counteract people's misperceptions by asserting their abilities as wheelchair racers.

This study illuminated the complexity and in some respects contradictive aspects of the way in which elite female wheelchair athletes construct their identities. However, further work needs to be done concerning how discourses of disability and gender interact in different sport activities on both competitive as well as non-competitive participation levels. Women with disabilities in Western countries usually have extraordinary social, economic and physical resources that are not available to most people with disabilities. Since it seems possible to minimize the disadvantages of disabilities through sports participation it would be of great interest to further examine the conditions of sports participation of women with disabilities in the developing countries.

\section{LITTERATURE}

- Asch, Adrienne \& Michelle Fine (1997): "Nurturance, Sexuality, and Women with Disabilities: The Example of Women and Literature", in Lennard J. Davis (Ed): The Disability Studies Reader. Routledge, New York and London.

- Blinde, Elaine M., \& Sarah G. McCallister (1999): "Women, Disability, and Sport and Physi- cal Fitness Activity: The Intersection of Gender and Disability Dynamics", in Research Quarterly for Exercise and Sport, 70(3).

- Butler, Judith (1999): Gender Trouble: Feminism and the Subversion of Identity. Routledge, New York and London.

. Corker, Mairian \& Sally French (1999): "Reclaiming discourse in disability studies", in Mairian Corker and Sally French (eds): Disability Discourse. Open University Press, Buckingham and Philadelphia.

. Craft, Diane H. (2001): "Impressions from Australia: The Sydney Paralympic Games", in Palaestra, 17(1).

- Davies, Bronwyn: (1997): "The post-structuralism: a reply to Alison Jones", in Gender and Education, 9(3).

- Davis, Lennard J. (1995): Enforcing Normalcy: Disability, Deafness and the Body. Verso, London and New York.

- DePauw, Karen P. (1997): "The (In)visability of DisAbility: Cultural context and 'sporting bodies"”, in Quest, 49.

- DePauw, Karen P., \& Susan J Gavron (1995): Disability and Sport. Champaign, IL: Human Kinetics Publishing.

- Engström, Lars-Magnus (1999): Idrott som social markör. HLS Förlag, Stockholm.

. Garland Thomson, Rosemarie (1997): "Feminist Theory, the Body, and the Disabled Figure", in Lennard J.Davis (ed): The Disability Studies Reader. Routledge, New York and London.

- Grey, Tanni (1997): "Elite Women Wheelchair Athletes in Australia", in Gill Clarke and Barbara Humberstone (eds): Researching Women and Sport. Mcmillan, Basingstoke.

- Guttmann, Ludwig (1976): Textbook of sport for the disabled. HM and M Publishers, Oxford.

- Hargreaves, Jennifer (2000): "Impaired and Disabled: Building on ability" in Heroines of Sport.

Routledge, New York and London.

- Patriksson, Göran (1982): Idrott, tävling, sambälle. Veje förlag, Örebro.

- Johansson, Ulla (2003): "Gatekeeper or creator of a cheerful school atmosphere? Construction of the good secondary school teacher on the state and the teacher' arenas: 1945-2000", paper presented at ECER, Hamburg, September 2003. - Jones, Alison (1997): "Teaching Post-structuralist Feminist Theory in Education: student resistances", in Gender and Education, 9(3).

- Kolkka, Tarja \& Trevor Williams (1997) "Gender and Disability Sport Participation: Setting a Sociological Research Agenda", in Adapted Physical Activity Quarterly, 14(1). 
- Mills, Sara (1997): Discourse. Routledge, New York and London.

- Morris, Jenny (1993): "Feminism and Disability", in Feminist Review, 43.

. Schell, Lea A. \& Margret C. Duncan (1999): “A Content Analysis of CBS's Coverage of the 1996 Paralympic Games", in Adapted Physical Activity Quarterly, 16.

- Scherrill, Claudine (1997): "Paralympic Games 1996: Feminist and Other Concerns: What's Your Excuse?", in Palaestra, 13(1).

. Thomas, Nigel \& Andrew Smith (2003): "Preoccupied With Able-Bodiedness? An Analysis of the British Media Coverage of the 2000 Paralympic Games", in Adapted Physical Activity Quarterly, 20

-Wendell, Susan (1989): "Feminism, Disability and Transcendence of the Body", Canadian Women Studies, 13(4).

- Wendell, Susan (1997): "Toward a Feminist Theory of Disability", in Lennard J.Davis (ed): The Disability Studies Reader. Routledge, New York and London.

\section{SUMMARY}

This paper focuses upon the meaning of being a female wheelchair racer at elite level. The paper is based on one-to-one semi-structured interviews with five female wheelchair racers, who all competed in the Paralympic Games 2000. This paper highlights the complexity and in some respects contradictive aspects of the ways in which elite female wheelchair athletes construct their identities. In this study the Paralympic Games are applied as a backdrop through which the athletes and their experiences are contemplated. Overall the research suggests that the interviewees cannot be contemplated as passive objects unable to affect their own lives. Rather they seem to be well aware of the logic of the discursine game and thereby manifest their independency through action and resistance. Thus they counteract people's misperceptions by asserting their abilities as wheelchair racers.

Kim Wickman, doktorand Pædagogiska institutionen Umeå Universitet 